
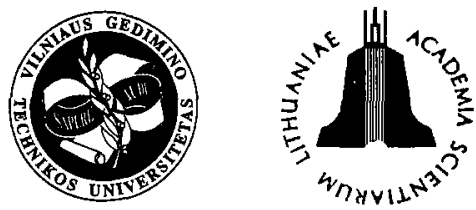

ISSN $1392-3730$

JOURNAL OF CIVIL ENGINEERING AND MANAGEMENT

http:/www.vtu.lt/english/editions

2003, Vol IX, No 3, 153-162

\title{
THERMO-HYDRAULIC FINITE ELEMENT MODELLING OF DISTRICT HEATING NETWORK BY THE UNCOUPLED APPROACH
}

\author{
Irena Gabrielaitienè ${ }^{1}$, Rimantas Kačianauskas ${ }^{2}$, Bengt Sunden ${ }^{3}$ \\ ${ }^{1,2}$ Dept of Strength of Materials, Vilnius Gediminas Technical University, \\ Sauletekio al. 11, LT-2040 Vilnius, Lithuania \\ E-mail: ${ }^{1}$ Irena.Gabrielaitiene@fm.vtu.lt, ${ }^{2}$ rkac@fm.vtu.lt \\ ${ }^{3}$ Lund University, Dept of Heat and Power Engineering, \\ Box 118,SE-221 Lund, Sweden. E-mail: Bengt.Sunden@vok.lth.se
}

Received 23 Jan 2003; accepted 09 Apr 2003

\begin{abstract}
The modelling of uncoupled fluid flow and heat transfer problems of a district heating network using the finite element method (FEM) is presented. Since the standard thermo-hydraulic pipe elements cannot be directly used for modelling insulation, the main attention was paid to discretisation of multilayered structure of pipes and surrounding by one-dimensional thermal elements. In addition, validity of the finite element method was verified numerically by solving fluid flow and heat transfer problems in district heating pipelines. Verification analysis involves standard single pipe problems and simulation of fragment of district heating in Vilnius. Pressure and temperature results obtained by finite element method are compared with those by other approaches.

Keywords: district heating network, FEM, uncoupled steady-state thermo-hydraulic flow.
\end{abstract}

\section{Introduction}

District heating distribution systems require careful design and construction to ensure the lowest maintenance and longest life. There are two problems concerning the design of fluid flow systems: sizing the pipe and determination of the flow-pressure relationship. Once a system has been sized, it should be analysed with more detailed methods of simulation to determine the hydraulic and thermal performance. The most significant factor that affects performance of systems is the consumer heat demand, settled by a minimum temperature level and quantity of heat, defined by the flow rate. Moreover, the energy transfer over long distances and distribution it to large areas unavoidably gives rise to both heat and pressure losses. Heat losses increase heat demand on the production unit and might cause a decrease of the water temperature level. Pressure losses require additional pumping power to achieve the desired flow at the consumer installations. Therefore the emphasis in this study is on advanced method for simultaneous modelling fluid flow and heat transfer.

The fluid flow in a pipe network poses a problem of a non-linear nature. This is due to the fact that the dependence of the flow rate and the pressure is non-linear. The main difference between methods of solving this problem lies in the selection of independent variables. The solution of heat transfer problem in thermo-hydrau- lic flow analysis contains difficulties due to the multilayered structure of the pipeline and due to different heat transfer modes having state-dependent characteristics. Some of these factors are neglected in engineering practice for simplicity reasons. Moreover, in heat transfer analysis convection and mass transport are related to fluid flow problem. Coupling of these two problems is of importance, when temperature-dependent fluid physical properties involved in both analyses are considered. The mentioned aspects require simultaneous modelling of fluid flow and heat transfer.

The modelling of fluid flow in district heating (DH) network has been investigated extensively. Flow solution for a single pipe or a tree network presents a trivial problem and may be obtained analytically. Existence of loops causes redistribution of the flow rate in pipes belonging to the closed loop, and the problem of flow distribution arouse. This incorporates a non-linear problem, because flow in pipes became unknown. The oldest and perhaps the most widely used method for analysing fluid flow in networks is the Cross method [1]. The method deals with each loop independently providing no direct interaction between the basic network equations. Zhao [2] investigated the concerned properties of two methods for steady-state flow analysis of DH networks: the linear theory method and the basic circuit method. Almkvist [3] adopted the method of characteristics to analyse complex pipe systems and simulated steady as 
well as transient flow behaviour. Valdimarsson [4] implemented the graph-theoretical method, which solves the non-linear equations for the loops, and flow solution of the network is obtained by a linearisation method.

After a hydraulic solution of the network is obtained, the estimation of heat transfer from hot water to surrounding is necessary, because it determines temperature drop, which in turn defines delivered temperature to the consumer. Due to fact that heat transfer takes place in moving fluid, flow and hydraulic regime must be considered in modelling. Although heat transfer generally is a transient three-dimensional phenomenon, for simplicity reasons the only steady-state mode is analysed. Twodimension approximation of heat transfer problem is usually used, when section in the pipeline are given $[5,6]$. In this analysis, the convection coefficient on both interior surface and on the exposed ground above the pipe has also been included in [7], while in [8] heat transfer problem was modelled for twin buried district heating pipes. To estimated heat transfer along the pipeline threedimensional models are required, which can be practically applied only for a single pipe, but not for a whole network.

In engineering approach, the fluid in pipe is modelled as a one-dimensional rigid mass motion, considering variables in the beginning and end of the pipe. Heat transfer from the hot water to surrounding soil is also considered as one-dimensional problem and solution are based on thermal resistance method, as was pointed out by Tuomas [9]. According to [10], two methods, the element method and the node method, have been used for physical modelling of temperature dynamics in district heating networks. The node method is related to simplified discretisation method, where all parameters are concentrated in nodes located through the pipe. In the element method the pipe is divided into a number of artificial elements and this method is similar to the finite element approach. Numerical analysis methods are practically applied for design of district heating pipelines. In Nordic countries they were realised in engineering programs, such as TERMIS [11] and NEXUS [12]. The simulation was performed due to a set of steady-state calculation and based on engineering simplifications. Although heat transfer problem in pipelines involves more than one heat transfer mode, the approach presented in the reference [11] combined various heat transfer coefficients into an overall coefficient, which is chosen from pipes specification. Thus the total heat transfer can be calculated from terminal temperatures.

The finite element method (FEM) is a powerful tool for fluid flow and heat transfer analysis, and it has been mostly applied for solving two- or three-dimensional problems. Classical approaches may be found in references [13-15]. Numerous works showed the application of FEM for specific problems, for example, the heat transfer and temperature distribution thought insulation and soil for a single pipe was analysed [7]. For solution of hydraulic problem in fluid network, FEM was applied in [16], while an in-house FE code was developed in [17] by approximation flow in pipes with 1D finite elements hocked together. The particularity of problems in $\mathrm{DH}$ network lies in an inconvenient application of 2D or 3D models due to enormous requirement of computer capacity. Therefore, there is a need for developing a more efficient FE model, which is able to compute the fluid flow and heat transfer analysis simultaneously. However, in commonly used FE codes such as ANSYS, standard FE cannot be applied directly, because of unvalued structure of the pipe and lack of implementation.

The emphasis of this report is to develop a FE approach in modelling thermal-hydraulic flow in insulated pipeline of district heating networks. Moreover, validity of the finite element method is verified by solving fluid flow and heat transfer problems in district heating pipelines. Simulation of fragment of DH network in Vilnius and comparison of results with other methods has been carried out as well.

\section{District heating network}

A district heating system distributes thermal energy from a central source to residential consumers by using pipelines through a closed loop network. The district heating systems can be divided into three parts (Fig 1): 1) plant, 2) the $\mathrm{DH}$ distribution or transmissions network and 3) the consumers where each individual consumer is defined as a heat exchanger and all installations on the secondary side of each substation.

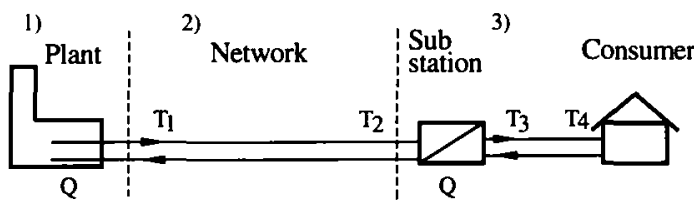

Fig 1. A schematic diagram of a DH systems

In general, district heating (DH) systems can be supplied from several heat production units and heat is transferred to many consumers with different requirements. The consumer uses the heat to maintain indoor temperature at a reasonable constant level, compensate for building heat loss to the environment, and for preparation of domestic tap water in substations, which separate the network into transmission and distribution parts.

The presented study is focused on the piping network that conveys the energy and is relevant to the common applications, ie the medium is hot water and the DH network consists of buried preinsulated pipes with carrier of steel, insulation of polyurethane and a casing of high-density polyethylene (Fig 2).

Model of district heating network is presented as a grid composed by one-dimensional segments. Important external parameters such as fluid flow rate can be set either to nodes of the grid or to segments. The load or demand of heat energy is expressed usually in terms of 


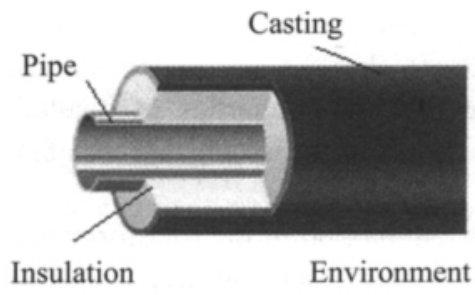

Fig 2. Common insulated pipe

heat flow at the nodes. The network structure refers to the data about the diameters of all pipes, their length and their roughness as well as where fittings are located.

Existing models for simulation of DH systems has been classified [18] 1) by type: models of the specific component of district heating systems, eg models for production unit (power plant and boilers); 2) by method: dynamic or steady-state; 3 ) by approach: physical, which refers to a knowledge of the nature of the district heating system, or black box models (for instance, time series and neural network models); 4) by usage: design, which focuses on predicting system performance or operation, referring to an optimisation problem.

Based on presented classification, the developed finite element model belongs to the type of models, which are focused on physical approach and allows simulating either transmission or distribution network (Fig 1), because the modelling of the substations is a subject of a separate study, eg [19]. By the classification by usage, the presented model focuses on the prediction of the main parameters of DH network, which indicates if the consumers' requirements can be satisfied. Although the fluid flow and heat transfer generally are dynamic phenomena, in the present study the steady state analysis is investigated as a necessary part of dynamic analysis of $\mathrm{DH}$ network.

\section{Fluid flow and pressure regime in pipelines}

In the treatment of steady-state flow analysis of district heating, networks aim at finding the flow distribution in a network when the network structure and the flow demand for all consumers are known. The solution process determines the flow rate in every pipe, pressure, etc at each node of the network.

The main factor affecting the pressure losses is the friction between the flowing water and adjacent wall. In addition, a local loss occurs due to disruption of the flow in valves, bends and other fittings. These losses are characterised by a local loss coefficient for each fitting and usually depend on the pipe diameter.

The basic principle for a single pipe is conservation of mass or the continuity principle, the work energy principle including the Darcy-Weisbach equation (1a) [20], which defines the relation between fluid friction and energy dissipation:

$$
\Delta p=f\left(\frac{L}{D}\right)\left(\frac{\rho V^{2}}{2}\right),
$$

where $\Delta p[\mathrm{~Pa}]$ - pressure drop; $f$ - friction factor, $L[\mathrm{~m}]$ - length; $D[\mathrm{~m}]$ - internal diameter; $\rho\left[\mathrm{kg} / \mathrm{m}^{3}\right]$ density; $V[\mathrm{~m} / \mathrm{s}]$ - velocity.

Friction factor describes friction occurring between the inner wall of a pipe and the flowing fluid within a pipe due to shear stresses at the interface. The friction coefficient is a function of the Reynolds number $R e$ and roughness of the surface $k$. In a numerical solution the Colebrook-White equation (1b) from [19] is used for estimation of friction factor $f$ :

$$
\frac{1}{\sqrt{f}}=-4 \cdot \log _{10}\left(\frac{k}{3,7 \cdot D}\right)+\frac{1,413}{\operatorname{Re} \sqrt{f}},
$$

where $k[\mathrm{~m}]$ - pipe wall roughness; $D[\mathrm{~m}]$ - diameter; $R e$ - Reynolds number.

Equation (lb) can be simplified and presented in its implicit formulation. For modelling the laminar flow, friction factor is described as a function of $R e$ number only.

As independent variables, the mass flow rates in pipes, the corrective mass flow rates in loops or the pressure levels can be selected for network solution. The set of equations, which consists of non-linear equations, must be solved simultaneously. The method employed in Newton-Raphson formulation, which considers the pressure level in nodes as unknown, is the method chosen here, because it converges rapidly to the solution.

Although the physical fluid properties, included in fluid flow analysis, are temperature dependent, in practical calculations those properties are evaluated at the fluid average temperature.

\section{Heat transfer}

Heat transfer takes place in pipe radial direction through insulation and surroundings, while in longitudinal pipe direction the mass transport phenomena occur, where flow regimes must be taken into account in modelling.

For the steady state conditions, heat balance equations for the single pipe are defined, using the heat transmission and thermal resistances formulation, which for a pipe section of length $\Delta x$ can be written as [10]:

$$
w C_{w} \Delta x \frac{\partial T_{w}}{\partial x}+{ }_{R}^{\Delta x}\left(T_{w}-T_{a p}\right)=0,
$$

where $T_{w}, T_{a p}$ - temperature of water and surroundings, $R$ - thermal resistance.

Thermal resistance is expressed in terms of sum of thermal resistance of each mechanical layer, because the heat transfer problem from fluid to surrounding ground constitutes a multistep process: from a warmer fluid to a wall, through the multilayered wall, then to a colder soil. 
Different transfer modes are involved to describe heat transfer in each medium; for instance, heat is transferred mainly via convection in water and thermal resistance is calculated by the following equation:

$$
R_{w}=\frac{1}{\pi d_{p} \alpha},
$$

where $\alpha$-convection heat transfer coefficient.

Because the temperature difference between wall and fluid is moderate, the estimation of the convection heat transfer coefficient is based on the Dittus-Boelter equation. This equation is applied for fully developed turbulent flow in smooth tubes, where the properties are evaluated at the fluid bulk temperature:

$$
N u=0,23 \operatorname{Re}^{0,8} \operatorname{Pr} 0,3,
$$

where $\operatorname{Pr}$ - convection heat transfer coefficient.

Although heat transfer through insulation is $2 \mathrm{D}$ problems, for practical estimation the heat losses are solved in the radial direction and it is assumed as one-dimensional (axi-symmetric) problem, which in radial coordinate can be written in the following form:

$$
\frac{d^{2} t}{d r^{2}}+\begin{aligned}
& 1 d t \\
& r d r
\end{aligned}=0,
$$

where $t$ - temperature; $r$ - radius.

Heat is transferred via conduction through the metal pipe, insulation and casing, and separate thermal resistance is to be defined for each materia. Thermal resistance can be estimated by equation (6), which follows from the equation (5)

$$
R=\frac{1}{2 \pi k} \ln \frac{d_{1}}{d_{2}},
$$

where $k$-thermal conductivity; $d_{1}$ and $d_{2}$ - external and internal diameters.

The thermal resistance of the ground was found by the superposition method, and Krischer first approximated the thermal resistance of the ground as a resistance of a cylinder of fixed size depending on the pipe diameter [21]. This mathematical approach is still commonly used today and is also applied in the present study.

\section{Uncoupled finite element approach to thermo-hy- draulic flow in pipe}

In the present study the analysis of fluid flow and heat transfer is based on the following assumptions:

1. The axial mixing of water in the pipe is disregarded and fluid flowing represents ID problem.

2. The heat transfer process from fluid to surroundings is only solved in the radial direction; therefore it presents a one-dimensional (axi-symmetric) problem.

3. The temperature rise due to the conversion of pumping energy into heat energy as a result of friction losses is neglected.
4. The material properties of the soil are homogeneous and phase changes are not considered.

5. The material properties of insulation structure and soil are assumed to be constant and temperature independent.

6. The assumption of the transformation of the thermal resistance at the ground surface to an equivalent layer of soil is applied.

7. Temperature of the surrounding ground of buried preinsulated pipe is assumed to be known (Fig 4).

Generally, the fluid flow in a pipe and heat transfer involving conduction and convection is a simultaneous phenomenon. Uncoupled thermo-hydraulic approach considers mechanical and thermal properties of fluid independently. It is assumed that the temperature gradient does not affect velocity and temperature profiles. This is equivalent to specifying that the properties of the water (density, viscosity, specific heat, thermal coefficient) remain constant in the flow. For an uncoupled thermalhydraulic model the equilibrium equations have the following form:

$$
\begin{gathered}
{\left[\boldsymbol{K}_{h}(\boldsymbol{P})\right]\{\boldsymbol{P}\}=\{\boldsymbol{W}\},} \\
{\left[\boldsymbol{K}_{l}(\boldsymbol{W})\right]\{\boldsymbol{T}\}=\{\boldsymbol{Q}\} .}
\end{gathered}
$$

Here, $\{\boldsymbol{P}\}$ and $\{\boldsymbol{T}\}$ present nodal pressure and temperature vectors, which are to be obtained by solution of the problem (7). Nodal fluid $\{\boldsymbol{W}\}$ and heat flow vectors $\{\boldsymbol{Q}\}$ describes the given external loads and boundary conditions. Hydraulic $\left[\boldsymbol{K}_{h}\right]$ and thermal matrices $\left[\boldsymbol{K}_{t}\right]$ present physical properties of the fluid and the insulation.

The one-dimentional thermo-hydraulic finite elements are most popular tools applied in numerical analysis of piping systems. However, these elements pay no attention to the pipe structure and surroundings, which are important in heat transfer analysis. Without considering of multilayered structure of pipeline and surrounding soil, it is impossible to evaluate thermal properties and actual boundary conditions under which heat transfer from the pipe occurs. Thermo-hydraulic element of ANSYS code [21] contains explicit heat transfer and friction models, which are not directly applicable for modelling heating networks. Thus, thermo-hydraulic element must be complemented with other elements in order to be applied for modelling district heating pipelines.

The first equation describes non-linear hydraulic flow, where hydraulic matrix $\left[\boldsymbol{K}_{l}\right]$ depends on the values of pressure difference. Due to the assumption of constant water properties, the second equation presents thermal linear problem. The thermal matrix $\left[\boldsymbol{K}_{l}\right]$ reflects conductivity, mass transport and convection.

The solution of model (7) requires an iterative procedure. $\Lambda$ fter solution of $(7 \mathrm{a})$, the obtained pressure vector is used as an input in (7b). The pressure and temperature gradient are solved through an itcrative process in which the matrices are updated at subsequent iteration steps. 


\section{Macroelement approach for multilayered pipe modelling}

\subsection{Basic concepts}

Generally discretisation of a pipe is referred to $2 \mathrm{D}$ or 3D fluid flow and heat transfer problems. In case of 2D problem, heat transfer analysis usually is performed in cross-sectional area of the pipe, without considering heat transfer in longitudinal pipe direction. Longitudinal heat transfer and fluid flow solution can be obtained by $3 \mathrm{D}$, which also enables to solve those problems simultaneously. However, for modelling district heating network discretisation of all pipes as $3 \mathrm{D}$ seems to be unrealistic due to large requirement of computer capacity [22]. Therefore simplified approaches dealing with reduced model and corresponding finite elements are explored for solutions of practical problems. Using this approach linear segment of the pipe is considered as a one-dimensional complex thermo-hydraulic element. The requirement of consideration of radial heat transfer in insulated structure of the pipes arises. This caused problems, because standard thermo-hydraulic pipe elements do not take into account the pipe structure.

Geometry of the complex macroelement is defined by nodes $I$ and $J$, while nodes $K$ and $L$ are used for surrounding soil. Inlet temperature is described by $T_{F}$, while outlet temperature by $T_{J}$ (Fig 3). The temperatures of environment $T_{K}$ and $T_{L}$ are assumed to be known. The thermo-hydraulic macroelement presents assembling of conventional element of the ANSYS code [23].

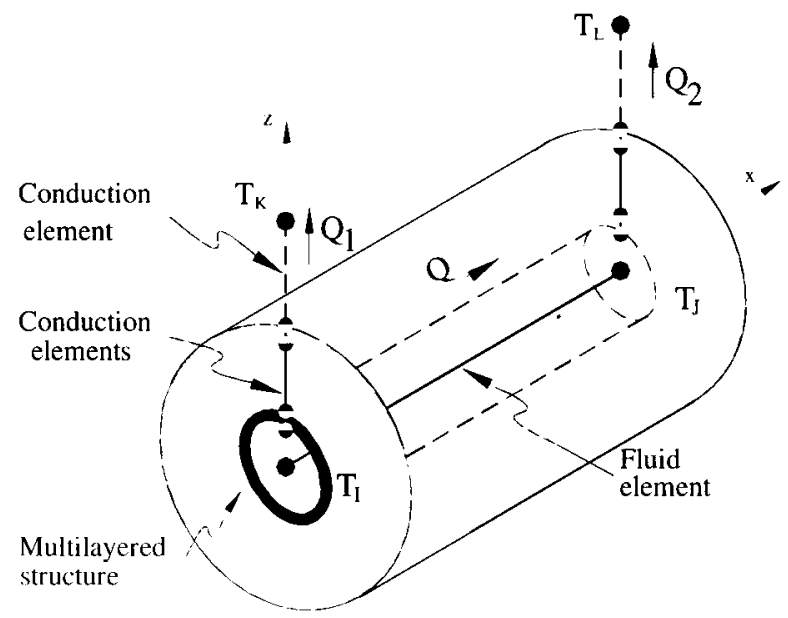

Fig 3. Complex thermo-hydraulic element

\subsection{Discretisation of hydraulic flow in pipelines}

For individual element, in our case macroelement $e$, the hydraulic matrix mainly depends on the fluid propcrties. This matrix expresses local losses and pressure losses due to friction:

$$
\left[\boldsymbol{K}_{h}^{e}\right]=\left[\boldsymbol{K}_{f}\right]+\left[\boldsymbol{K}_{z}\right],
$$

where $\left[\boldsymbol{K}_{f}\right]-$ frictional pressure losses; $\left[\boldsymbol{K}_{z}\right]$ - local pressure losses.

Estimation of frictional pressure losses is referred in [20], where friction coefficient includes fluid physical properties and define the simplified form of Eq ( $1 \mathrm{~b})$.

\subsection{Discretisation of thermal flow in pipelines}

The physical nature of the thermal matrix is much more complicated. The thermal matrix reflects heat transfer by fluid along the pipe as well as through a multilayered, or even multisolid, structure of the pipe and environment. For an individual element $e$ it may be presented as a sum of different layers:

$$
\left[\boldsymbol{K}_{t}^{e}\right]=\sum_{m=1}^{p}\left[\boldsymbol{K}_{m}^{e}\right],
$$

where subscript $m$ represents the layer of insulation.

Each layer (eg insulation, surrounding soil) produces thermal resistance described in Eqs (3) and (6).

On the other hand, individual layers may contain different transfer modes. In general, each layer may produce a thermal matrix:

$$
\left[\boldsymbol{K}_{m}\right]=\left[\boldsymbol{K}_{c n v}(\boldsymbol{T})\right]+\left[\boldsymbol{K}_{\text {mass }}(\boldsymbol{P})\right]+\left[\boldsymbol{K}_{c n d R}(\boldsymbol{T})\right]+\left[\boldsymbol{K}_{c n d L}(\boldsymbol{T})\right],
$$

where $\left[\boldsymbol{K}_{c n v}(\boldsymbol{T})\right]$ - convection matrix; $\left[\boldsymbol{K}_{\text {mass }}(\boldsymbol{P})\right]$ - mass transport matrix; $\left[\boldsymbol{K}_{c n d L}(\boldsymbol{T})\right]$ and $\left[\boldsymbol{K}_{c n d R}(\boldsymbol{T})\right]$ conduction matrices in the flow longitudinal direction and normal to the flow direction, respectively.

Thermo-hydraulic fluid element describes fluid flow and heat transfer from fluid to a wall. The behaviour of flowing fluid is described by hydraulic matrix $\left[\boldsymbol{K}_{h}\right]$ in Eq (9). The thermal component is described by thermal matrix $\left[\boldsymbol{K}_{t}\right]$. The component is characterised by energyaverage fluid temperature across the pipe and temperature of the layer adjacent to internal surface of the pipe. The fluid presents a single layer $m$, for thermal matrix is presented as a particular case of $\mathrm{Eq}(10)$ :

$$
\left[\boldsymbol{K}_{m}\right]=\left[\boldsymbol{K}_{c n v}(\boldsymbol{T})\right]+\left[\boldsymbol{K}_{\text {mass }}(\boldsymbol{P})\right]+\left[\boldsymbol{K}_{c n d L}(\boldsymbol{T})\right] .
$$

Convection component $\left[\boldsymbol{K}_{c n v}(\boldsymbol{T})\right]$ is estimated through flow dependent convection film coefficient $h(T)$, which may be evaluated from Eq (4) accordingly to [24]. Estimation of conduction component $\left[\boldsymbol{K}_{c n d L}(T)\right]$ incorporates the thermal conductivity of the flow.

Moreover, a set of conduction elements is required to present the transfer of heat in the pipe, insulation and casing material. Since properties of each material are different, thermal matrices describe thermal resistance of each layer.

For describing conduction in the insulation, the following matrix, which incorporates thermal resistance in Eq (6), is used:

$$
\left[\boldsymbol{K}_{m}\right]=\left[\boldsymbol{K}_{c n d R}\right] .
$$

For describing the conduction through the soil the transformation of the thermal resistance at the ground 
surface to an equivalent layer of soil is performed and thermal matrix has the form (11). The soil is considered as a single layer and depth of the pipe is taken as a thickness of layer (Fig 4). Evaluation of thermal resistance of the soil can be calculated as [20]:

$$
R_{g}=\frac{1}{2 \pi k} \ln \left(\frac{2 H}{d}+\sqrt{\left(\frac{2 H}{d}\right)^{2}-1}\right.
$$

where $k$ - thermal conductivity of the soil; $d$ - diameter of insulated pipe; $H$ - equivalent depth of the pipe defined as $H=l_{g}+0,0685 k ; l_{g}$ - distance from the ground surface to the pipe centre.

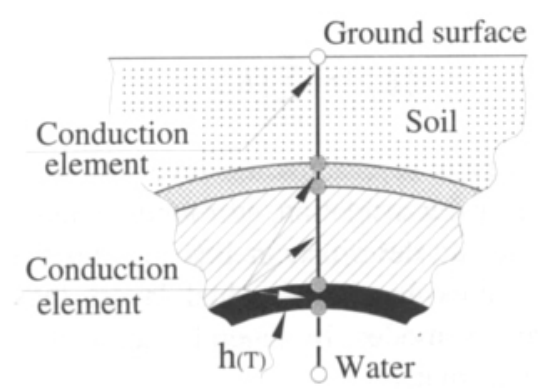

Fig 4. Set of thermal finite elements to describe multilayered structure of insulated pipe and surrounding soil

The model presented in Fig 4 produces temperature results on the internal and external surfaces of the pipe, insulation and casing. However, if the temperature distribution within the insulation and casing material (or soil) is required, different models are to be applied, for details see [25]. The presented FEM implies a method of thermal resistances, and it does consider non-linear temperature distribution through insulation.

\section{Accuracy of finite element model}

In order to ensure the correct thermal solution, the actual pipe was divided into a number of finite elements in the pipe longitudinal direction, thus water temperature and heat losses are recalculated in each element (Fig 5).

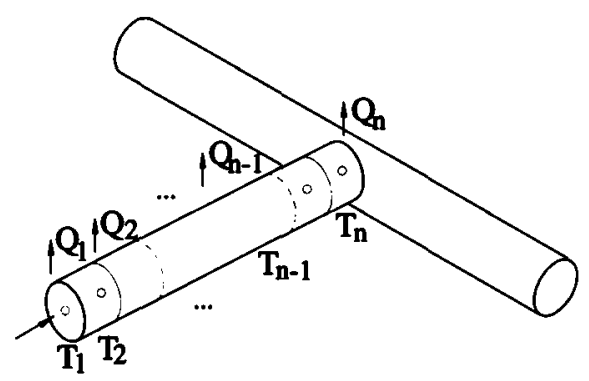

Fig 5. Example of subdivision of actual pipe into elements; $\mathrm{Q}$ - heat losses, $\mathrm{T}$ - temperature of water
Subdivision of an actual pipe into elements was investigated by performing numerical experiments for different pipe diameters and flow rates. Longitudinal subdivision of the pipe does not influence the results of the hydraulic solution (ie pressure losses), while it may significantly affect the results of thermal analysis. In order to investigate how the subdivision influences the temperature results, a test for a pipe with a length of $1 \mathrm{~km}$ and diameter $500 \mathrm{~mm}$ has been carried out. The test was repeated when the number of elements in pipe longitudinal direction changes from 2 to 128 .

The outlet temperature estimated by an analytical method has been compared with the corresponding temperature obtained by finite element (FE) calculations (Fig 6). This test was repeated for different flow rates: $\mathrm{W}=80 \mathrm{~kg} / \mathrm{s}$ and $\mathrm{W}=100 \mathrm{~kg} / \mathrm{s}$. The influence of flow velocity on the temperature results shows a decrease in accuracy for the lower velocity at the same level of discretisation. These differences tend to vanish with increasing number of elements in the pipe longitudinal direction.

It can be concluded that thermal flow is strongly dependent on the number of elements and lower flow rate requires a high density of discretisation. The reason for this is a low velocity of hot fluid, which makes the function of non-linear distribution more arched. As a result, a larger number of finite elements is required in order to represent this function precisely.

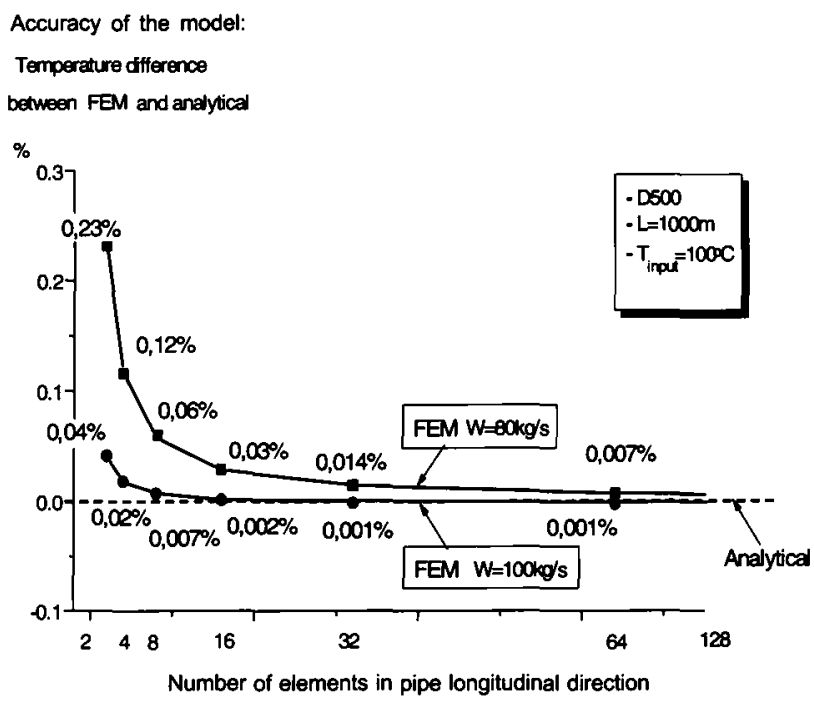

Fig 6. Accuracy of the temperature results as a function of number of elements; where FEM - finite element method, $w$ - mass flow in the pipe

\section{Case study: modeling of district heating network in Vilnius}

A case study is performed to demonstrate the idea discussed in the previous sections. The fragment of district heating network has been simulated by FEM. These results have been compared to the results obtained by 
the approach widely used in practical engineering, ie TERMIS software.

In the present study, data from the district heating system in Vilnius, Lithuania, are used. Fig 7 shows the distribution network of the system. There is one DH plant and 18 heat exchanger substations (consumers). The DH network is set up of preinsulated pipes buried underground and all connected buildings are situated within an area of $3,6 \mathrm{~km}^{2}$. Results between two mentioned approaches were compared in points $\mathrm{B}, \mathrm{C}$, and $\mathrm{D}$ in the network (Fig 7).

Heat is transferred by water at an initial temperature $T_{i}=100^{\circ} \mathrm{C}$ at the district heating station and temperature of surrounding ground is $T_{g r}=5^{\circ} \mathrm{C}$. The pipe dimensions range from 500 to $600 \mathrm{~mm}$.

The fluid physical properties, such as fluid mass density, specific heat, and fluid viscosity are known. Their values are chosen assuming the average temperature of the water in the $\mathrm{DH}$ pipelines, $T_{o}=80^{\circ} \mathrm{C}$. This is the design temperature used for planning $\mathrm{DH}$ system.

Material properties used in a simulation can be found in Table.

Steady state analysis of the DH network is referred to finding the flow, pressure and heat losses. The deliv-

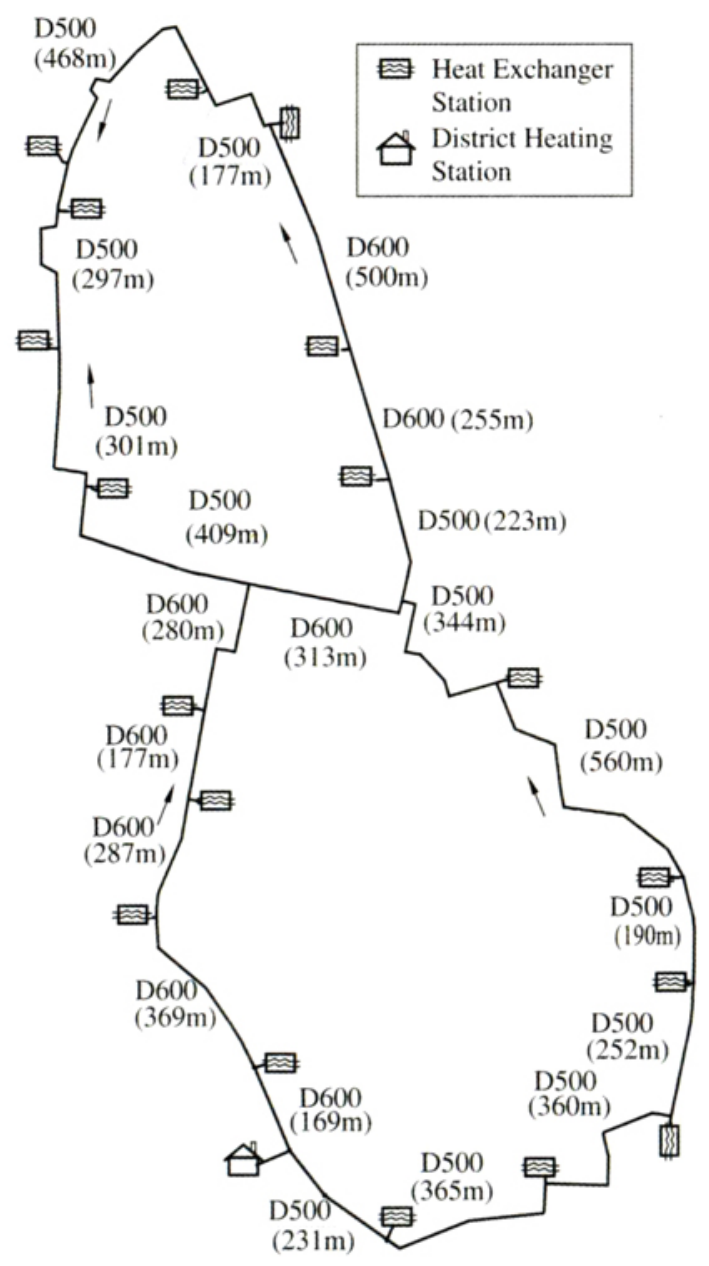

Fig 7. Fragment of Vilnius district heating system
Material properties

\begin{tabular}{|l|l|l|l|l|}
\hline Material & $\begin{array}{l}\text { Density } \\
{\left[\mathrm{kg} / \mathrm{m}^{3}\right]}\end{array}$ & $\begin{array}{l}\text { Specific } \\
\text { heat } \\
{[\mathrm{J} /(\mathrm{kg} \mathrm{K})]}\end{array}$ & $\begin{array}{l}\text { Thermal } \\
\text { cond. } \\
{[\mathrm{W} /(\mathrm{m} \mathrm{K})]}\end{array}$ & $\begin{array}{l}\text { Viscosity } \\
{[\mathrm{kg} /(\mathrm{ms})]}\end{array}$ \\
\hline Water & 1000 & 4200 & 0,68 & 0,0003 \\
\hline Steel & - & - & 50 & - \\
\hline $\begin{array}{l}\text { Insula- } \\
\text { tion }\end{array}$ & - & - & 0,0275 & - \\
\hline Casing & - & - & 0,38 & - \\
\hline Soil & - & - & 2,7 & - \\
\hline
\end{tabular}

ered water temperature at each consumer is also estimated, when the network structure, pipe size and the flow demand at each consumer are known.

\section{Comparison between uncoupled approach and ap- proach used in practical engineering}

The district heating network (Fig 7) was calculated by the analytical approach used in engineering and presented by Tuomas [9]. The simulation by the finite element method has been also carried out. In a case when the temperature drop in pipelines is less than $5 \%$ [9], temperature usually is not recalculated along the pipe-

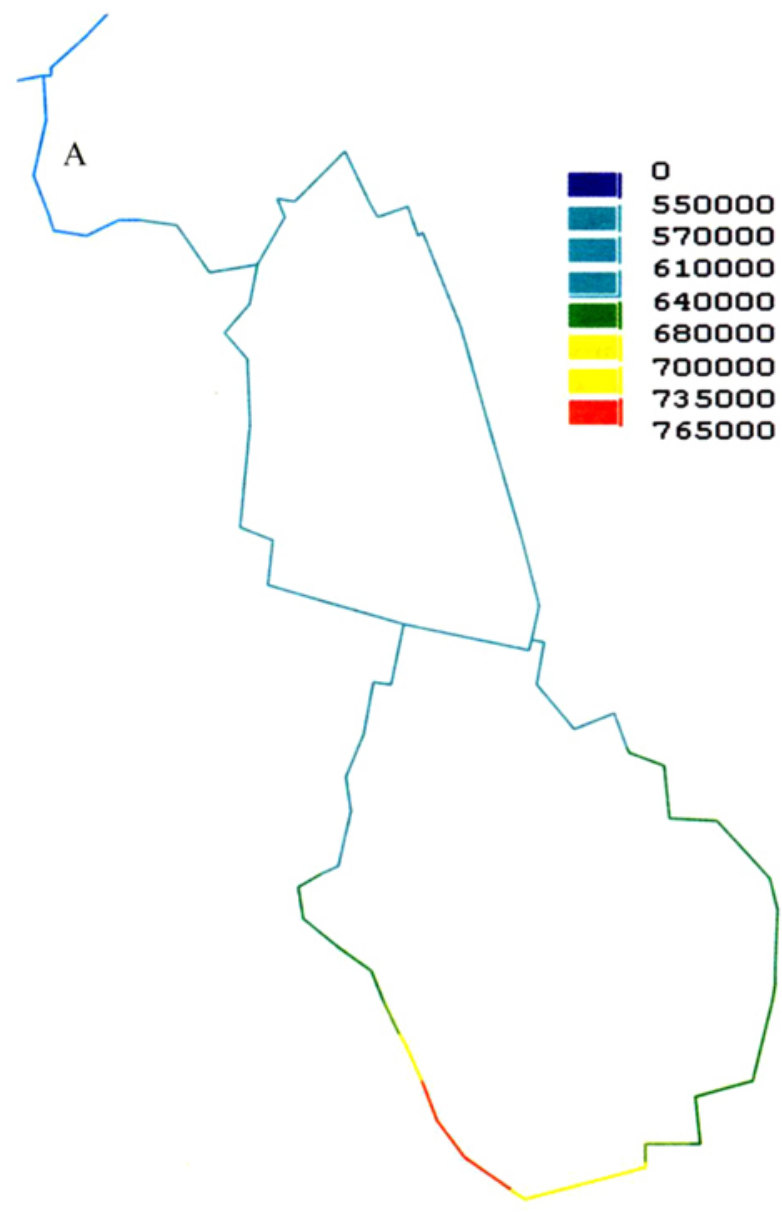

Fig 8. Pressure distribution in fragment of district heating network in Vilnius 


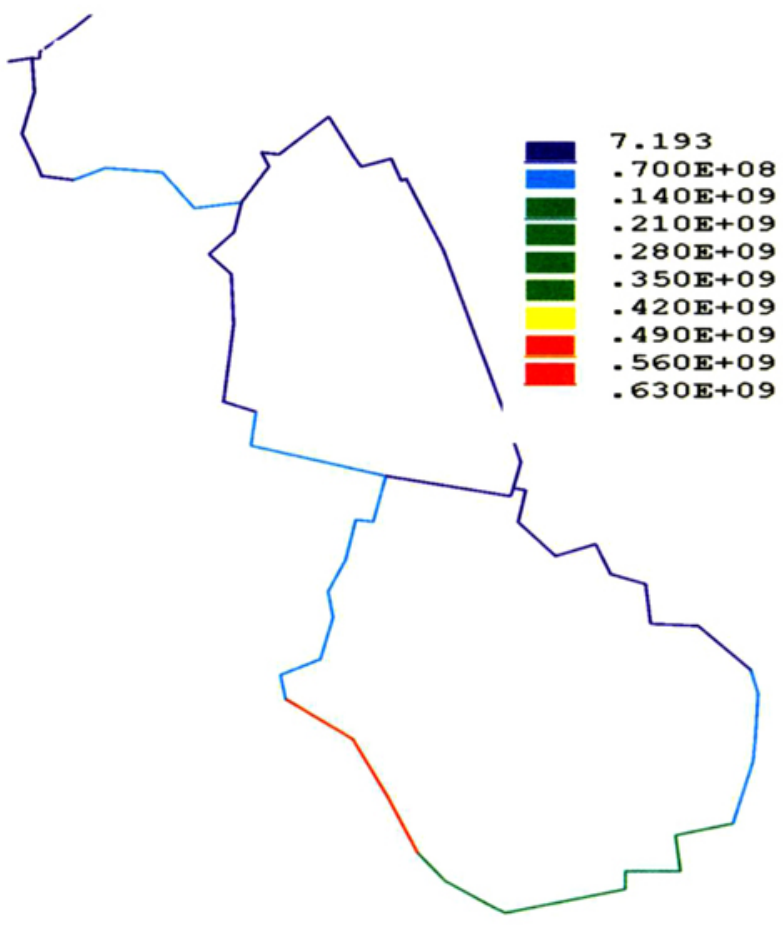

Fig 9. Distribution of heat transfer in a fragment of district heating network in Vilnius

lines in the mentioned engineering approach. This is the main cause for the difference between results of both approaches in temperature distribution and heat losses (for the details see [26]). For a separate segment of the pipelines with different diameters, the results of thermal analysis were investigated in [25].

Fig 8 presents the pressure distribution in a network of Vilnius, and, as it can be seen, pressure decreases dramatically through the network and reaches the lowest value at point $A$. Fig 9 shows heat transmission term described in Eq 5 . Heat transmission distributes not sequentially in fragment of district heating network in Vilnius, due to its relation to fluid flow which has similar distribution.

Fig 10 shows the temperature results obtained by finite element model for a single pipe. Red line represents temperature in the centre of pipe. Vertical lines represent the temperatures of the insulation structure in the beginning and end of the pipe. By the changes in colour we can see how temperature decreases from $80^{\circ} \mathrm{C}$ in metal pipe surface (red part in the vertical lines) to about $36^{\circ} \mathrm{C}$ in external insulation surface (light blue part in vertical lines). The lowest temperature of $5^{\circ} \mathrm{C}$ represents the temperature of the soil surrounding the pipe.

The modelling of previously mentioned fragment of DH network in Vilnius has been also carried out by the TERMIS software [version 1.2], which nas constructed especially for hydraulic and thermal simulation DH systems. The simulation was performed due to a set of steady-state calculation and described in the manual [11]. The hydraulic analysis is based on estimation of pressure loss, which is the sum of frictional pressure loss

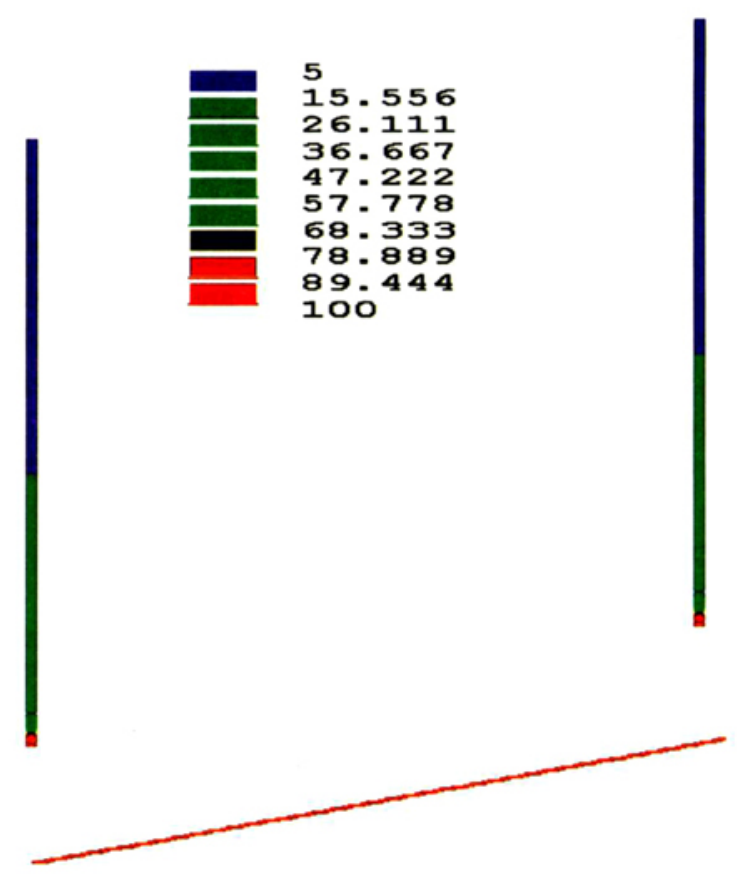

Fig 10. Temperature distribution in the fragment of insulated pipe and surrounding

and singular loss. The friction factor is calculated on the basis of Colebrook and White's formula [19]. When the flow of the entire network is known the temperatures and heat losses in the network are calculated.

The model applied for simulation in TERMIS software has the simplification in determination of heat losses, and as a result of this simplification the overall heat transfer coefficient is to be chosen for each pipe from pipe specifications, such as [27]. The overall heat transfer coefficient of the pipes in the DH network was calculated by a finite element model and then inserted into TERMIS database.

Figs 11 and 12 show the comparison of the current results and the results obtained by TERMIS.

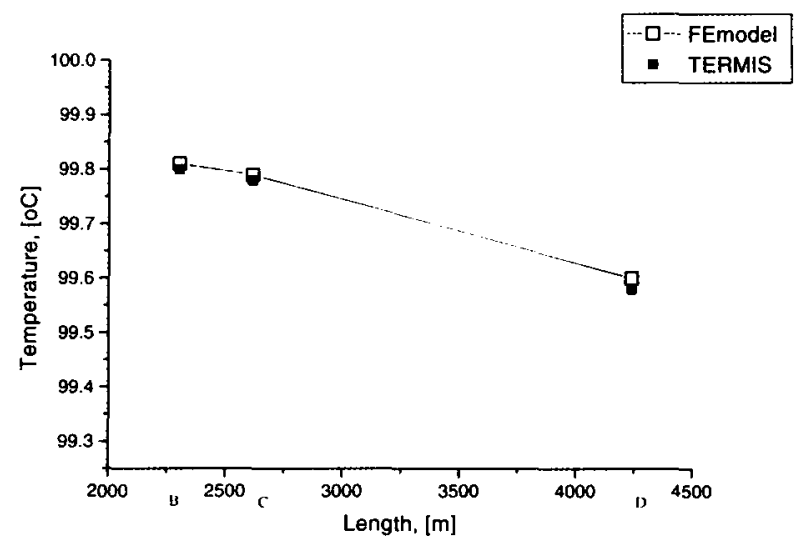

Fig 11. Comparison of temperature distributions between the finite element model (FE) and TERMIS; B, C, and D are characteristic points in the network (Fig 8) 
The approach employed in TERMIS and set out in the manual [11], combined the heat transfer coefficients of the insulation structure and surrounding ground into an overall heat transfer coefficient.

The temperature distribution in Fig 10 illustrates the fragment of insulated pipe and surrounding, which location in Fig 7 by characteristic nodes B, C and D.

The difference between the heat losses obtained by TERMIS and the finite element model is insignificant and does not exceed $1 \%$ (Fig 12).

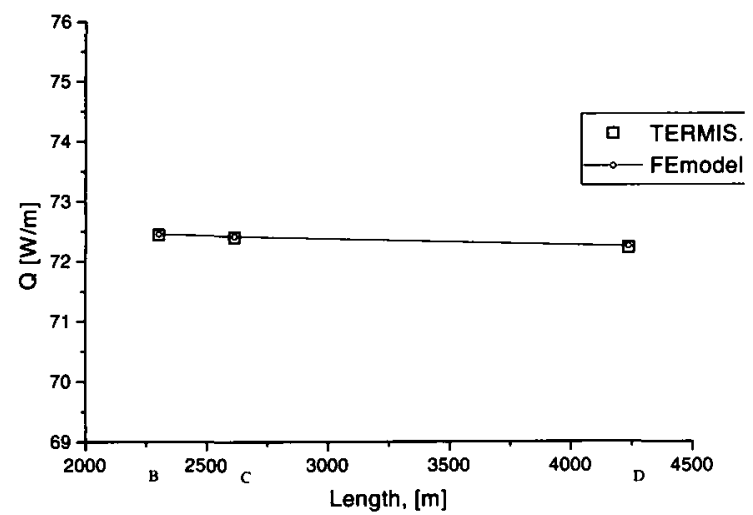

Fig 12. Comparison of heat losses between finite element model (FE) and TERMIS; B, C, and D are characteristic points in the network (Fig 8)

The main factor affecting the pressure losses is the friction coefficient, which is a function of $R e$ number and roughness. In the numerical solution by TERMIS, the implicit Colebrook-White's equation is applied for estimating the friction coefficient, while in the finite element model the modified Colebrook-White equation in its explicit formulation is used. This results in a small difference between the results of pressure losses obtained by TERMIS and the finite element model.

From the steady-state simulation of a fragment of the district heating network by the TERMIS software and the finite element model it can be concluded that the simulation results show a small difference in frictional losses and temperature distribution between the methods.

Without any doubt, the best way to validate the model is to compare the simulated results with the measured data. For a single pipe or separate part of the network this does not present difficulties, but it is problematic to find measurements, which have been performed for a whole network particularly with loops due to a) additional expenses related to the experiments, $b$ ) it might be not enough to measure temperature of the water in a pipe. Measurements of the surrounding ground should be performed, as well as material properties of buried pipes. Otherwise, the discussion of validation of the model will end up with a discussion concerning difficulties in comparison of the results due to a lack of experimental data.

\section{Conclusions}

The finite element approach for analysis of fluid flow and heat transfer in district heating network has been developed. Theoretical investigation and numerical examples prove suitability of the above approach:

1. Since traditional engineering approaches as well as on this basis developed method are related to particular cases of heating pipelines or particular mathematical models, the finite element method is universal tool independent of the structure of the network geometry and it seems to be prospective for applying in simulation of heating networks.

2. In spite of wide possibilities and principal advantages, the existing universal finite element codes cannot be directly applied to thermo-hydraulic analysis of district heating networks.

3. The macroelement approach is proposed for discretisation of multilayered structure of the pipe, which works by combining of simplified thermo-hydraulic pipe element and one-dimensional thermal elements and is implemented by users' utilities into the ANSYS environment. On the basis of numerical experiment performed for the segment of the pipelines, it is possible to have a model describing thermal properties of the pipe structure and surroundings.

4. Numerical investigation of longitudinal discretisation shows that hydraulic flow is independent of a number of elements. Temperature results are affected by descretisation level, and also depend on flow rate. It is concluded that the longitudinal discretisation with 8 elements per pipe of $1 \mathrm{~km}$ is sufficient for engineering purpose and shows $0,007 \%$ of accuracy. However, error is higher for low water velocities and shows $0,06 \%$ accuracy for the same pipe.

5. Comparison of the current solution with a solution by analytical approach used in practical engineering, presents generally the same picture of temperature distribution and heat losses for district network of Vilnius. However, estimation of heat losses in engineering approach is based on assumption, that if temperature drops in a network less than $5 \%$, the changes in temperature are neglected. This assumption leads to an increase in heat losses.

6. Comparison of current finite element results with solution by TERMIS software shows identical temperature field for the fragment of the real network of Vilnius. However, thermal resistances of the pipe, insulation and equivalent layer of soil in TERMIS are required a priori, while finite element model simulates temperature field in pipe simultaneously.

7. The proposed pipe element, discretisation technology and experience gained may be used not only for simultaneous solution of uncoupled fluid and heat flow but also can be extended to model unsteady flow. This allows to take into account changes in supply temperature, transient effect on heat losses and variations of climate. 


\section{Acknowledgement}

For the financial support, the first author wishes to thank the members of the scientific council in Programme on Energy Flexible Heating Systems, within the Nordic Energy Research Programme, as well as the Programme secretary. The financial support from the Swedish Institute is also gratefully acknowledged. Authors also thank Vilnius District Heating Company (Vilniaus šilumos tinklai) for providing data used in the study.

\section{References}

1. Stephenson, D. Pipeline design for water engineers Elsevier Scientific Publishing Company, New York, 1981. $320 \mathrm{p}$.

2. Zhao, H. Analysis, modelling and operational optimisation of district heating systems. Lab. of Heating and Air Conditioning, Technical University of Denmark, Lyngby, 1995. $226 \mathrm{p}$.

3. Almkvist, S. Calculation of transient flow in complex pipe systems, chalmers university of technology. Department of Thermo- and Fluid Dynamics, Gothenburg, 1991. 63 p.

4. Valdimarsson, P. Pipe network flow models - comparison of a solution and a graph theoretical solution. In: Proc. of the $8^{\text {th }}$ inter. symposium on district heating and cooling, August 14-16, 2002, Trondheim, Norway, p. 1-15.

5. Sunden, B. Computational convective and conductive heat transfer. In: Advanced computational method in heat transfer VI, eds. B. Sunden \& C. A. Brebbia. Publ. by Witpress Southampon, Boston, 2000, p. 1-17.

6. Huebner, K. N.; Thornton, E. A. The finite element method for engineers. John Wiley and Sons. New York, 1982. $623 \mathrm{p}$.

7. Schneider, G. E. An investigation into heat loss characteristics of buried pipes. Journal of heat transfer, transactions of ASME, Vol 107, August 1985, p. 696-699.

8. Jonson, E. Heat losses from district heating system in small areas - Influence of pipe geometry and dimension. Lund Institute of Technology, Sweden, 2001. $76 \mathrm{p}$.

9. Tuomas, E.; Gedgaudas, M. Heating supply (Šilumos tinklai). Vilnius, 1993. 328 p. (in Lithuanian).

10. Palsson, H. Methods for planning and operating decentralized combined heat and power plants, Riso National Laboratory, Roskilde, Technical University of Denmark, Denmark, 2000. $199 \mathrm{p}$.

11. TERMIS Manual Version 1.2, Seven Technologies A/S. 2002. 187 p.
12. District Heating International Trade Fair, Stockholm, 8-10 October 2001.

13. Baker, A. J. Finite Element Computational Fluid Mechanics. New York: McGraw-Hill, 1983. 453 p.

14. Vaitiekūnas, $P$. Numerical modelling of convective transport (Konvekcinio pernešimo skaitinis modeliavimas). Lithuanian energy institute, 1998. 264 p. (in Lithuanian).

15. Zenkiewicz, O. C. The Finite Element Method. London: McGraw-Hill, 2000. 785 p.

16. Moaveni, S. Finite element analysis. Theory and application with ANSYS. Publ. by Prentice-Hall, Inc. 1999. 527 p.

17. Kutas, R.; Čiupailaitè, E. The finite element approach for the analysis of flow in pipe network. In: Proc. of XIII Polish Conference on Computer Methods in Mechanics, 5-8 May 1997, Poznan, Vol 2, p. 719-726.

18. Valdimarsson, P. Modelling of geothermal district heating systems. University of Iceland - Haskolautgafan, Reykjavik, Iceland, 1993. $120 \mathrm{p}$.

19. Wollerstrand, J. District heating substations: performance, operation and design. Lund Institute of Technology, Department of Heat and Power Engineering. Doctoral thesis, 1997. $202 \mathrm{p}$.

20. ASHARE. District heating and cooling. Heating, Ventilating, and Air-Conditioning Systems and Equipment, American Society of Heating, Refrigeration and Air Conditioning Engineers, Inc: Atlanta, 1996, p. 11.1-11.23.

21. Bohm, B. On transient heat losses from buried district heating pipes. Int. Journal of Energy Research, No 24, 2000, p. 1311-1334.

22. Kačianauskas, R. Computer Methods in Multilevel Modelling of Beams and Shells. Vilnius: Technika, 1995. 395 p.

23. ANSYS. Theory Reference. Release 5.7. 2001 SAS IP, Inc. ()

24. Holman, J. P. Heat transfer, $8^{\text {th }}$ ed., McGraw-Hill, Inc. 1997. 689 p.

25. Gabrielaitienė, I.; Kačianauskas, R.; Sunden, B. Analysis of Heat Losses in Multilayered Structures of a Pipeline Using Finite Element Method. In: Proc. of the $14^{\text {th }}$ Nordic Seminar on Compt. Mechanics, Lund, Sweden, Ed: Sadberg, G, 2001, p. 157-160.

26. Gabrielaitienè, 1.; Kačianauskas, R.; Sunden, B. Application of the Finite Element Method for Modelling of District Heating Networ. In: Proc. of 2nd Worldwide ECCE Symposium, Pub. by Association of Finish Civil Engineers RIL, Finland, 2001, p. 279-284.

27. Quality Pipes EN 253. Quality Standards for district heating pipes. Preinsulated bonded pipe systems (EuHP). Avenues de Cortenberg 66, B-1040 Bruxelles, Belgium, 1997. 